\title{
Características de infiltração de água nos solos da várzea do rio Paraíba do Sul, em Tremembé, SP
}

\author{
Christian Kather ${ }^{1}$ \\ Hélio Nobile Diniz ${ }^{2}$ \\ Marcelo dos Santos Targa ${ }^{2}$ \\ Getulio Teixeira Batista ${ }^{2}$ \\ Eduardo Miralha Rodrigues ${ }^{1}$
}
${ }^{1}$ Secretaria de Agricultura e Meio Ambiente da Prefeitura de Tremembé
Rua Sete de Setembro, 701 - 12120-000 - Tremembé - SP, Brasil
\{ckather, meioambiente\}@tremembe.sp.gov.br

\author{
${ }^{2}$ Programa de Pós-Graduação em Ciências Ambientais da Universidade de Taubaté \\ Estrada Mun. Dr. José Luiz Cembranelli, 5.000 - 12080-010 - Taubaté - SP, Brasil \\ heliodiniz1@yahoo.com.br \\ \{gtbatista,mtarga\}@unitau.br
}

\begin{abstract}
.
The infiltration of water in the floodplain of the Paraíba do Sul river is a natural mechanism that promotes the conservation of the hydrographic basin water resources by decreasing the loss of water by runoff or evaporation. The two main economic activities developed in the floodplain of the Paraíba do Sul river are irrigated rice crop and sand mining. Both cause great loss of surface water by evaporation due to large plots of rice and abandoned sand mining pits filled with water. This research aimed to investigate water infiltration into the soil covered with different cover types in the floodplain of the Paraíso sand extraction port, Tremembe municipality, Paraíba do Sul river basin. Five infiltration tests were conducted in the area, including: close to the rice plot, abandoned and operational port sand sites. In general, the soil had low permeability and the infiltration velocity was practically insignificant. However, in the area of natural forest and pasture vegetation the permeability was higher than in the rice and sand pits.
\end{abstract}

Palavras-chave: Dinâmica de Infiltração, rizicultura, extração de areia, anel concêntrico, permeabilidade, Rio Paraíba do Sul.

\section{Introdução}

A infiltração da água no solo compreende uma dinâmica natural por meio do deslocamento da água superficial disponível que percola nos interstícios porosos do solo, verticalmente devido à gravidade. $\mathrm{O}$ conhecimento desta dinâmica, na área da várzea do rio Paraíba do Sul, no município de Tremembé, propicia estimativas do comportamento da água utilizada para o plantio de arroz irrigado e da capacidade de recarga dos recursos hídricos nesse local.

A estimativa da taxa de infiltração de um solo é importante para o cálculo do excedente hídrico no balanço hidrológico e contribui para o entendimento do escoamento superficial e da velocidade de penetração da lâmina d'água em projetos de irrigação e drenagem.

As duas principais atividades econômicas desenvolvidas na área da várzea do rio Paraíba do Sul, a rizicultura e a mineração de areia, produzem grande perda de água superficial, devido à evaporação das extensas lâminas d'água expostas durante longos períodos de tempo.

A rizicultura se instalou em Tremembé pela boa disponibilidade hídrica e porque os terrenos de várzeas são propícios ao desenvolvimento deste tipo de cultura, que é a principal atividade agrícola remanescente no município (KATHER, 2005).

A extração de areia na área da várzea do rio Paraíba do Sul, para uso na construção civil, corresponde a $10 \%$ da produção nacional e equivale a $1.023 .836 \mathrm{~m}^{3}$ mensais (DNPM, 2005), 
respondendo por cerca de $25 \%$ da produção areeira do Estado de São Paulo (REIS et al., 2006). A extração de areia no Vale do Paraíba teve seu início no final da década de 1940 no município de Jacareí. Ao longo do tempo, esta atividade provocou a supressão da vegetação nativa e o aumento da vulnerabilidade do lençol freático junto às margens do rio Paraíba do Sul, principalmente na região compreendida entre as cidades de Jacareí e Tremembé (KATHER, 2005).

Pela classificação de Köppen, o clima de Tremembé é Cwa, ou seja, o clima é úmido, com temperaturas quentes no verão e inverno ameno. A temperatura média do mês mais frio é em torno de $18^{\circ} \mathrm{C}$, apresenta um período seco no inverno, sendo a temperatura média nos meses de verão em torno de $22^{\circ} \mathrm{C}$. A precipitação do mês de julho é aproximadamente $10 \%$ da precipitação do mês de janeiro (FISCH, 1995).

\section{Objetivo}

O objetivo do presente trabalho é estimar a infiltração proveniente de fontes superficiais em diferentes locais da várzea do rio Paraíba do Sul, no município de Tremembé, SP, próximos das áreas de extração de areia e plantios de arroz irrigado.

\section{Material e Métodos}

A área em estudo denominada Porto de Areia Paraíso, localiza-se em Tremembé, Vale do Paraíba, Estado de São Paulo, constituída de uma topografia plana localizada entre os municípios limítrofes de Monteiro Lobato, Taubaté e Pindamonhangaba. O recurso hídrico principal é o rio Paraíba do Sul, que corta o município de leste a oeste. Seus afluentes diretos no município são os rios Piracuama, Verde e Serragem, sendo estes dois últimos com nascente no próprio município.

O município de Tremembé é considerado Estância Turística, desde 27 de Dezembro de 1993, de acordo com a Lei Estadual 8.506/93. Fundado em 1896, atualmente possui uma população de 34.807 habitantes, dos quais cerca de 29.850 residem no setor urbano e 4.957 nas áreas rurais. A área do município possui um total de $192,4 \mathrm{~km}^{2}$, conferindo uma densidade demográfica de 180,9 hab/ $\mathrm{km}^{2}$. Tremembé está localizada a $133 \mathrm{~km}$ de São Paulo e $309 \mathrm{~km}$ do Rio de Janeiro, próximo à rodovia Presidente Dutra (BR-116). Neste município têm ocorrido conflitos pelo uso da água entre os diversos setores de atividade econômica tais como, rizicultura irrigada, extração de areia em cavas, indústrias e pesque-pagues.

\section{Método de Campo}

Foram realizados testes de infiltração de água no solo em cinco locais na área do Porto de Areia Paraíso (Figura 1), em Tremembé, o qual apresenta áreas de cava ativas e inativas intercaladas por diques divisores, áreas de mata ciliar e áreas de cultivo de arroz. Para medições de infiltração foi utilizado o método de infiltrômetro de anéis concêntricos conforme (BERNARDO, 1982) e discutiram-se os resultados da infiltração de acordo com Reichardt (1987).

O método de determinação da velocidade de infiltração e infiltração acumulada descrito em Bernardo (1982), consiste no cravamento de dois anéis concêntricos no solo, sendo que o anel externo tem função de suprimir o efeito da dispersão lateral da água infiltrada no anel interno para possibilitar a estimativa da taxa de infiltração vertical da água. Deve-se manter uma lâmina d'água de aproximadamente $15 \mathrm{~cm}$ no anel interno e as leituras são efetuadas a intervalos de tempos regulares em uma régua verticalmente posicionada na parede do anel interno. 
Os testes de infiltração efetuados nesta pesquisa tiveram a finalidade de analisar a dinâmica subsuperficial da água em áreas temporariamente inundadas para rizicultura e áreas permanentemente inundadas pelas atividades de extração de areia.

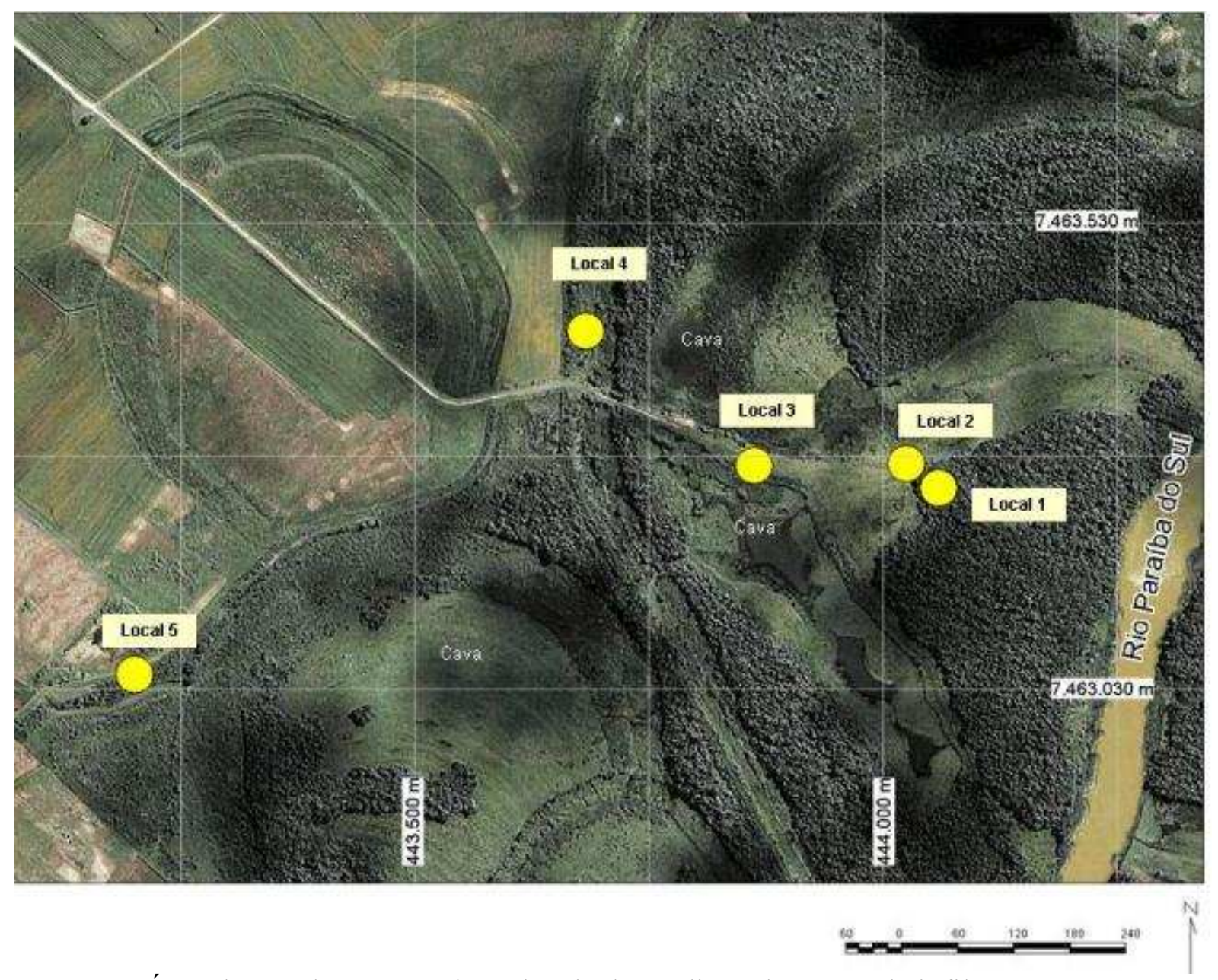

Figura 1. Área de estudo mostrando os locais de medição das taxas de infiltração.

\section{Caracterização dos solos}

Ocorrem três grupos distintos de solos em Tremembé-SP, segundo (OLIVEIRA et al., 1999) os terrenos mais elevados são classificados como Cambissolos Háplicos Distrófico, associados com Latossolo Vermelho Amarelo Distrófico. Na parte central do município, em relevo menos acentuado, ocorre Latossolo Amarelo Distrófico, associado com Latossolo Vermelho Amarelo Distrófico, e nas partes baixas ou áreas de várzea ocorre o Gleissolo Melânico Distrófico, associação com Organossolos Distróficos e Neossolos Flúvicos.

Nos principais canais de drenagem da região está bem desenvolvido um sistema fluvial meandrante, associado a gradientes moderadamente baixos, fluxo contínuo e regular. Os sedimentos aluvionares são constituídos por argilas, siltes e areias conglomeráticas.

No rio Paraíba do Sul é identificado, em fotografias aéreas, antigos meandros abandonados, ou seja, antigas posições do curso fluvial principal que, em épocas pretéricas, foram preenchidos com sedimentos terciários da Bacia Sedimentar de Taubaté. As espessuras desses sedimentos mais recentes não ultrapassam uma dezena de metros. 
Devido ao fato do município de Tremembé apresentar grandes extensões de várzeas ao longo do rio Paraíba do Sul, a erosão hídrica causada por escoamento superficial não constitui um processo frequente. A elevada concentração de areia no sub-solo do município retém muita água abaixo do horizonte orgânico e em cima de uma camada de argila bentonítica, a argila verde. Nos processos de extração de areia por cava submersa, a dragagem é feita até a argila, o que garante a separação da água do lençol freático das águas dos aquíferos confinados. Visando promover o levantamento de dados representativos da área de estudo, estabeleceu-se nesse trabalho um esquema de distribuição dos pontos de amostragem, que são assim descritos:

Local 1: Esse local apresenta-se coberto por mata ciliar e situa-se a cerca de 30 metros do Rio Paraíba do Sul, composto por mata primária de diversas espécies. O solo nessas áreas é formado basicamente por um Gleissolo Melânico Distrófico em associação com Organossolos Distróficos e Neossolos Flúvicos.

Local 2: Esse local situado a menos de 10 metros de distância da mata ciliar do rio Paraíba do Sul é totalmente coberto com vegetação de Brachiaria decumbens. Embora esse local seja cercado com arame farpado, observou-se leve pastoreio de gado no local. O solo é caracterizado por um Latossolo Amarelo Distrófico, associado com Latossolo Vermelho Amarelo Distrófico.

Local 3: Esse local fica em um aterro de uma cava abandonada situada a 5 metros de um divisor de cavas e a aproximadamente 250 metros da mata ciliar do Rio Paraíba do Sul. O solo é de aterro e composto, basicamente, por um Latossolo Vermelho Amarelo com característica argilosa. Foi observada a presença de Brachiaria decubens e para a realização do teste foi feita a limpeza do local com uma enxada para não desagregar o solo.

Local 4: Nesse local ocorre cobertura vegetal composta basicamente por Brachiaria decubens, algumas plantas daninhas como guanxuma, tiririca e mudas de árvores nativas em processo lento de regeneração, com no máximo $25 \mathrm{~cm}$ de altura. $\mathrm{O}$ solo é composto basicamente por um latossolo vermelho amarelo distrófico apresenta um desnível de 3 metros da lamina d'água da rizicultura irrigada e situada a 4 metros da mesma. Para o procedimento de medição da infiltração foi necessária a limpeza do local com auxílio de uma enxada com cuidado para não desagregar o solo.

Local 5: Esse local do teste, próximo de uma valeta de drenagem situado a 20 metros de uma cava de areia em plena atividade apresenta um solo composto basicamente por Latossolo Vermelho Amarelo argiloso.

\section{Resultados e Discussão}

Os testes de infiltração foram realizados em um tempo de aproximadamente 100 minutos e no geral mostraram que o solo, na área da várzea do rio Paraíba do Sul, possui diferentes comportamentos em função do tipo de solo e do uso e cobertura.

No teste realizado no Local 1 , com cobertura de mata ciliar densa, a velocidade de infiltração observada variou de $1,2 \mathrm{~cm} / \mathrm{min}$ no início para $0,07 \mathrm{~cm} / \mathrm{min}$ no final do teste (Figura 2). Constatou-se uma dinâmica hídrica de boa infiltração para o lençol freático e altos índices de armazenamento hídrico sendo classificada como velocidade de infiltração muito alta (REICHARDT, 1987), capaz de armazenar no solo uma lâmina acima de $200 \mathrm{~mm}$ ao final do teste. Houve, nos primeiros minutos de testes, a necessidade de reposição de água nos anéis concêntricos em função da alta velocidade de infiltração. Atribui-se essa maior infiltração à existência de Floresta Ombrófila Mista e à baixa compactação e boa permeabilidade devido à presença de raízes no perfil do solo. 


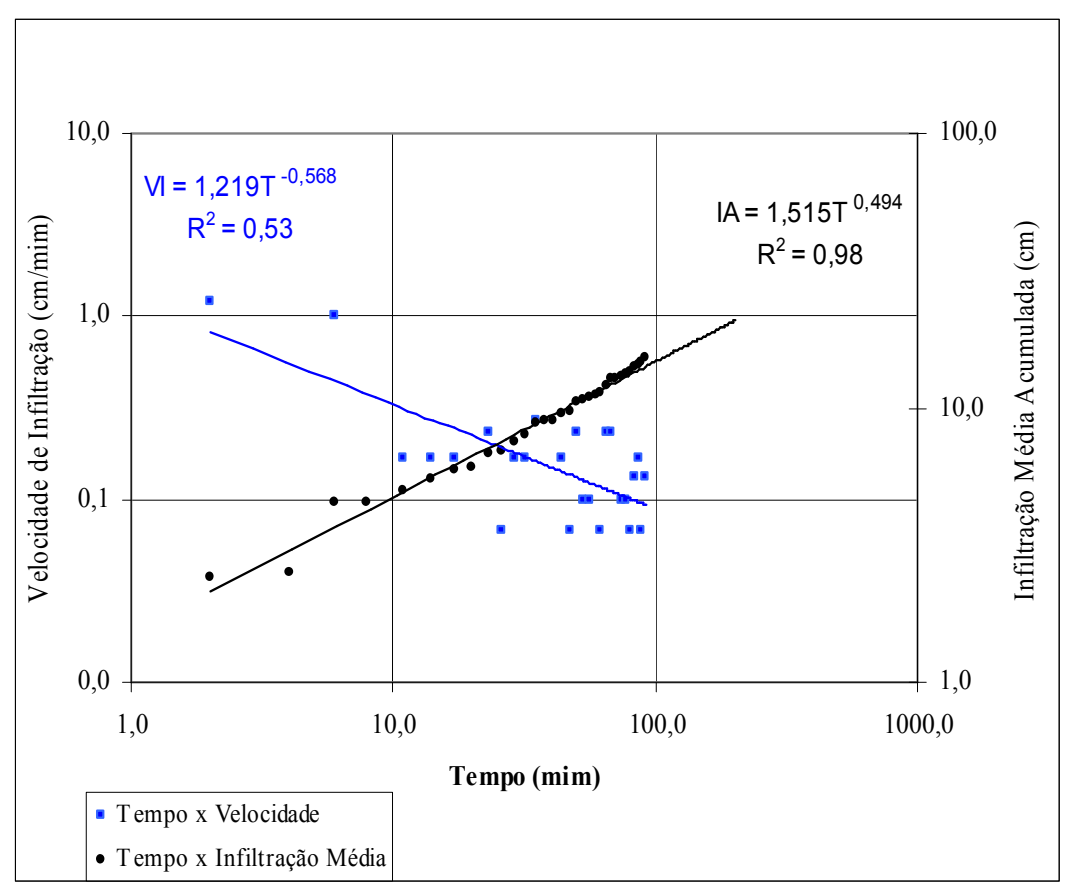

Figura 2. Infiltração acumulada e velocidade da infiltração no Local 1.

No teste realizado no Local 2, situado a menos de 10 metros de distância da mata ciliar do rio Paraíba do Sul (Figura 1) apresentou uma percolação bem mais baixa do que a do Local 1 $(0,45 \mathrm{~cm} / \mathrm{min}$ a $0,07 \mathrm{~cm} / \mathrm{min}$; Figura 3), também classificada como velocidade de infiltração muito alta (REICHARDT, 1987) e que foi capaz de armazenar no solo uma lâmina acima de $200 \mathrm{~mm}$ ao final do teste. Essa elevada infiltração deve ser atribuída à proximidade e influência da mata ciliar. No local verificou-se a presença da forrageira Brachiaria decumbens compondo uma pequena área de pastagem.

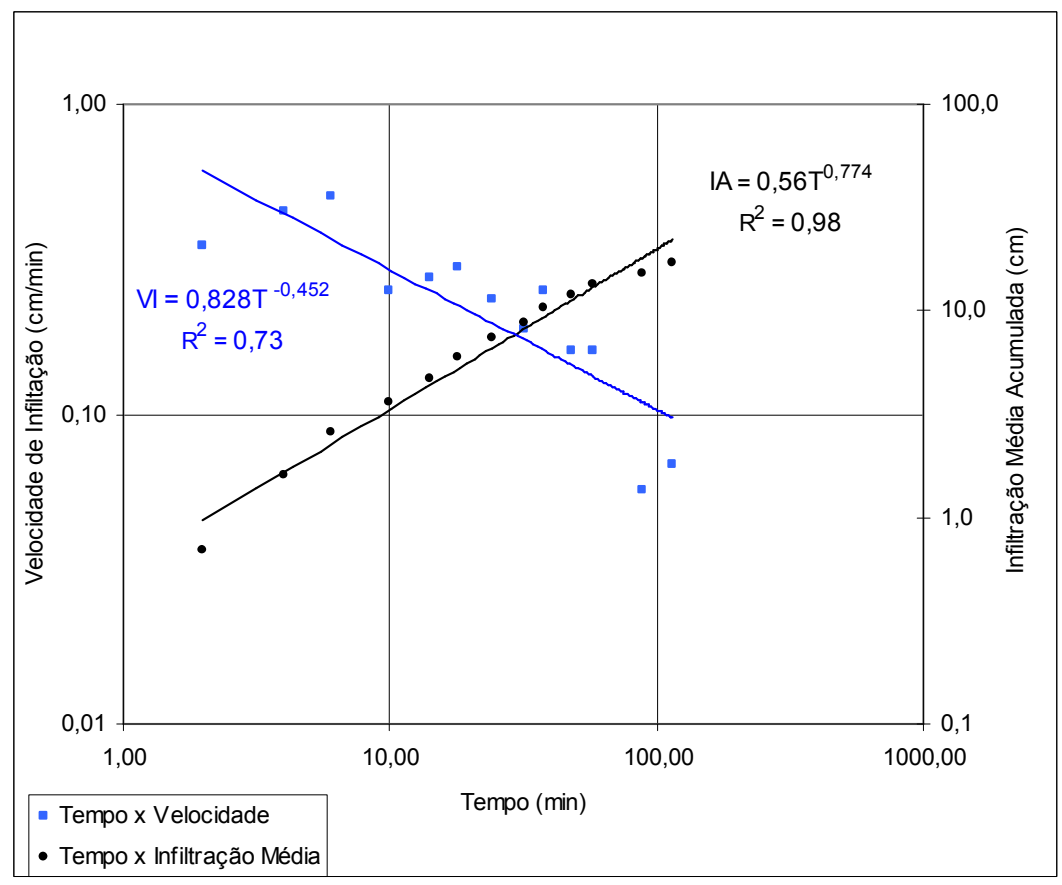

Figura 3. Infiltração acumulada e velocidade da infiltração no Local 2. 
No teste realizado no Local 3, situado em um divisor de cavas, foi observada uma velocidade de infiltração básica de $0,07 \mathrm{~cm} / \mathrm{min}$ (Figura 4), classificada como alta (REICHARDT, 1987) sendo capaz de armazenar cerca de $36 \mathrm{~mm}$ de lâmina de água no solo ao final do teste.

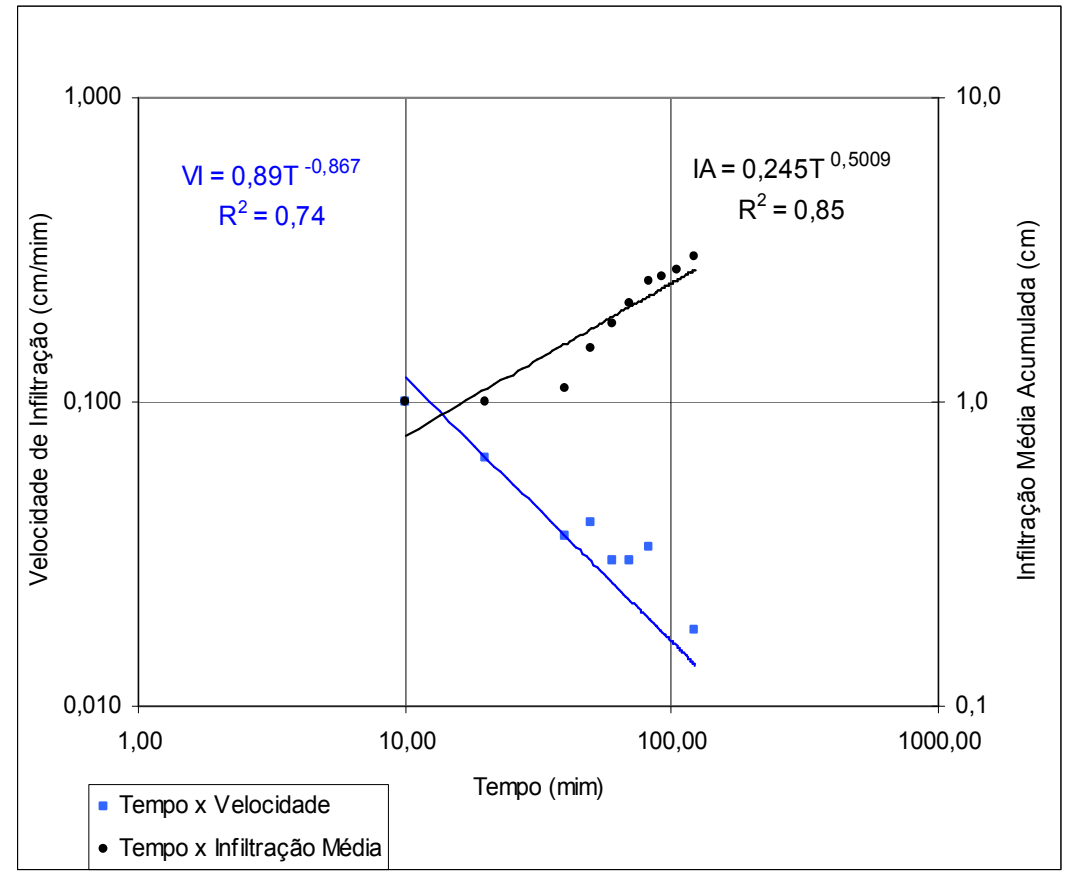

Figura 4. Infiltração acumulada e velocidade da infiltração, Local 3.

O teste realizado no Local 4, próximo à área de rizicultura, o solo apresentou velocidade de infiltração básica média (REICHARDT, 1987), variando de $0,15 \mathrm{~cm} / \mathrm{min}$ no início do teste até $0,01 \mathrm{~cm} / \mathrm{min}$ no final do teste (Figura 5), quando acumulou uma lâmina de $36 \mathrm{~mm}$ de água no solo. Essa área é representativa dos solos de várzea e favorece ao cultivo de arroz por inundação nos tabuleiros.

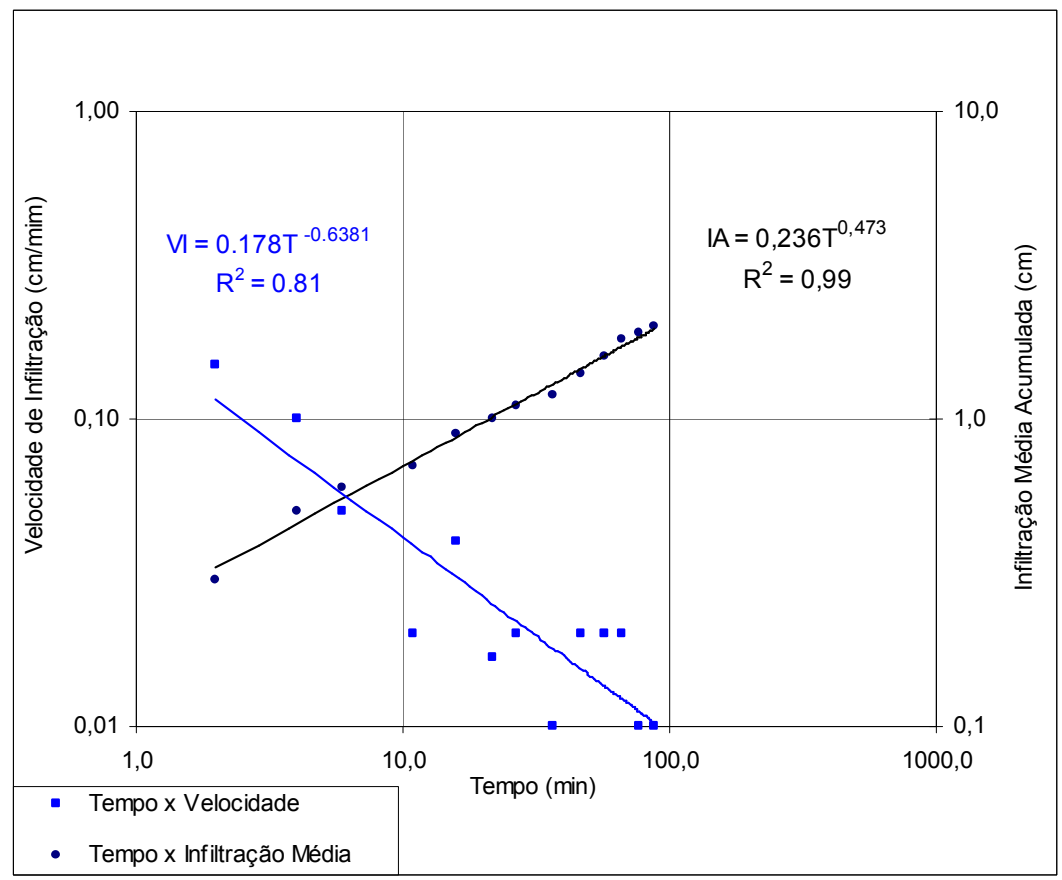

Figura 5. Infiltração acumulada e velocidade da infiltração, Local 4. 
O teste realizado ao lado da cava em atividade (Local 5) apresentou velocidade de infiltração básica de água no solo classificada como média (REICHARDT, 1987). Nos primeiros minutos a velocidade de infiltração foi de $0,30 \mathrm{~cm} / \mathrm{min}$ e diminuiu drasticamente, chegando a $0,01 \mathrm{~cm} / \mathrm{min}$, indicando uma rápida saturação do perfil do solo e capacidade de acumular uma lâmina de $25 \mathrm{~mm}$ de água no solo.

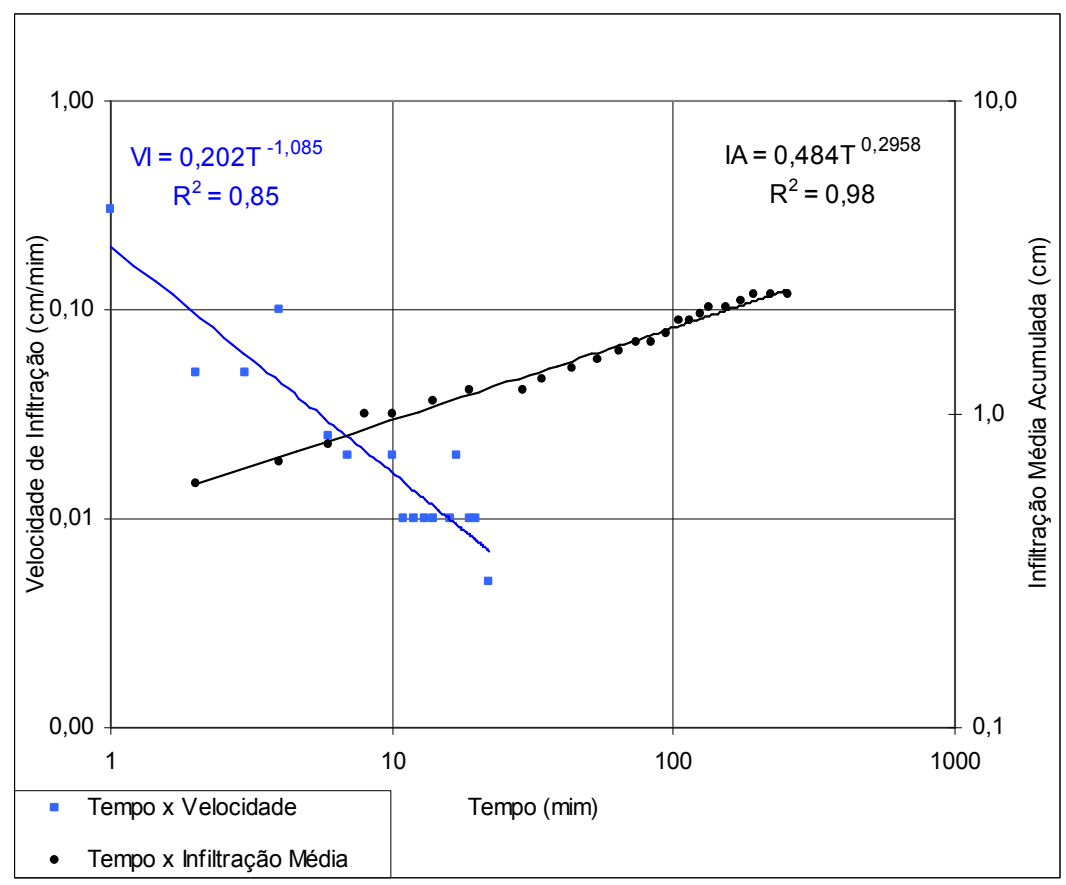

Figura 6. Infiltração acumulada e velocidade da infiltração, Local 5.

\section{Conclusão}

As taxas de infiltração básica observadas na área de estudo foram consideradas elevadas. $\mathrm{Na}$ área de floresta e próxima dela (Locais 1 e 2) a média da velocidade de infiltração foi maior do que em outros locais, indicando que a infiltração acumulada na mata ciliar é muito importante para a perenidade do rio Paraíba do Sul.

\section{Referências Bibliográficas}

BERNARDO, S. Manual de Irrigação. 2a Ed. Viçosa-MG. Imprensa Universitária. 1982. $463 p$.

DNPM - Departamento Nacional da Produção Mineral. Anuário Mineral Brasileiro. Brasília: Departamento Nacional da Produção Mineral, 2005. v. 34, 426 p.

FISCH, G. Caracterização climática e balanço hídrico de Taubaté, São Paulo. Revista Biociências, v. 1, n. 1, p. 81- 90, 1995.

OLIVEIRA, J. B.; CAMARGO, M. N.; ROSSI, M.; CALDERANO FILHO, B. Mapa pedológico de São Paulo, Escala 1: 500.000. Campinas: Instituto Agronômico/EMBRAPA - Solos, 1999. 
KATHER, C. Estudo do escoamento superficial na bacia hidrográfica do ribeirão Serragem no Vale do Paraíba do Sul. Dissertação (Mestrado em Ciências Ambientais) Universidade de Taubaté, Taubaté, 2005. 116 p.

REIS, B. J.; BATISTA, G. T.; TARGA, M. S.; CATELANI, C. S. Influência das cavas de extração de areia no balanço hídrico do vale do Paraíba do Sul. Rev. Esc. Minas, 2006, vol. 59, n. 4, p. 391-396. 